\section{PARTICIPATE IN TOBACCO PREVENTION ACTIVITIES IN 2014}

As World Oral Health Day (WOHD) 2015 approaches on 20 March, FDI World Dental Federation wants people to make a healthy New Year's resolution and reduce their use of tobacco - or give it up completely - as part of the 'Smile for life' campaign.

The use of tobacco can significantly increase the risk of many serious oral health problems: oral cancer, gum disease, premature tooth loss, tooth discoloration, bad breath, and reduced ability to taste and smell.

The use of tobacco, including smokeless tobacco, and excessive consumption of alcohol, are the key risk factors in oral cancer and together are estimated to account for 90\% of oral cancers worldwide. This percentage could be significantly lowered through a reduction in the use of tobacco and alcohol intake.

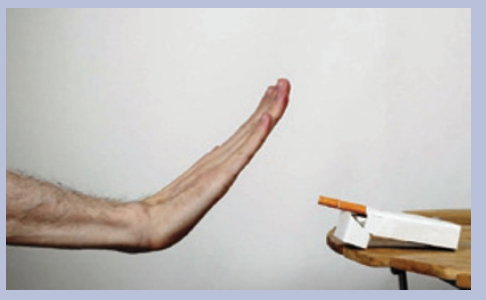
The FDI would also like to encourage health professionals to participate in tobacco

prevention activities. Dentists and their teams can help communicate important messages to patients about the threats posed by tobacco use and help them to identify the key risk factors and the early signs of oral cancer, as well as gum disease and other oral health problems, in their early stages.

Patients may not always recognise early symptoms, so the FDI and its partners: Listerine, Unilever, Henry Schein and the Wrigley Oral Healthcare Program, encourage people of all ages to schedule regular check-ups with their dentists.

Find out more at www.worldoralhealthday.org.

\section{ACCESS TO IMPLANT SYSTEM LIBRARY}

3Shape, a global leader in 3D scanners and CAD/CAM software solutions, is proud to announce that 3Shape Implant Studio users now have access to the original Straumann Dental Implant System library.

Dentists, implantologists and dental technicians will be able to access the original library of Straumann dental implants when using 3Shape Implant Studio. The Straumann library includes Straumann's bone and tissue level and ceramic implant systems.

Users who wish to benefit from this opportunity should contact their 3Shape distributor for more information on how to access these libraries.

The original implants must be obtained from Straumann. To find Straumann contact information in your area, see http://www.straumann.com/en/home/ about-straumann/worldwide-locations.html.

\section{PEPPERMINT SCENTED DENTAL GLOVES}

Clinical waste management and infection control expert Initial Medical is now supplying peppermint scented gloves to the dental sector.

Prolonged glove use and repeated hand washing can cause the skin to become dry and chapped, making those working in the dental industry more susceptible to dermatitis. Unigloves Green LANO-E gloves, available from Initial Medical, contain a microfilm of lanolin and vitamin $\mathrm{E}$ to soothe and soften the skin on the hands of the wearer.

Designed specifically for the dental market, Unigloves Green LANO-E gloves provide the very highest protection, while having the added benefit of being peppermint scented to increase patient experience - helping to reassure them they are being examined in a clean, safe environment. With a fully textured surface for increased grip, the gloves are 100\% latex, low allergy and rated medical grade AQL 1.5.

Initial Medical is also marketing two water line cleaners for dental practitioners. Sterisil Citrisil and Citrisil Blue tablets continuously disinfect and maintain dental water lines. Using distilled or purified tap water, these tablets effervesce to provide a safe, $\mathrm{pH}$ balanced treatment.

The Sterisil Straw and Antimicrobial Bottle is the perfect solution for transitioning from daily tablets to a single yearly change out. The Sterisil Straw works 365 days to continuously disinfect dental unit water lines and provide safe and clean water.

For further information or to order visit www.initialmedical.co.uk or telephone 08007310802.

\section{CHECK FOR AN ACCURATE PROSTHETIC FIT}

Fit Checker Advanced and Fit Checker Advanced Blue are Vinyl PolyEther materials for checking pressure spots and the fit accuracy of prosthetic works. Thanks to the very thin consistency, sharp setting time and hydrophilicity, both materials are very convenient to use and offer an accurate identification of misfits of prosthetic works of all kinds. The choice between two transparent well contrasting colours allows an easy evaluation of any type of prosthesis: blue, for aesthetic restorations such as ceramic based crowns and bridges and for occlusal checking; and white, for metal based restorations and dentures.

Fit Checker Advanced \& Fit Checker Advanced Blue has a thixotropic consistency with easy flow under pressure; minimal film thickness for a precise seat of the restoration; visible colour gradation for easy identification of misfits; increased hardness to allow smooth and easy trimming with bur; and high tear resistance for easy removal.

Fit Checker Advanced has a white colour for checking the fit of metal based restorations and dentures and is available in handmix and automix cartridge.

Fit Checker Advanced Blue has a transparent blue colour that allows an analysis of the occlusal situation, even under $100 \mu \mathrm{m}$ thickness and is available in automix cartridge for precise and optimised application. For further information contact GC UK on 01908218999. 